ARTICLE

DOI: $10.1038 /$ s41467-018-05883-1

\title{
Solar superstorm of AD 774 recorded subannually by Arctic tree rings
}

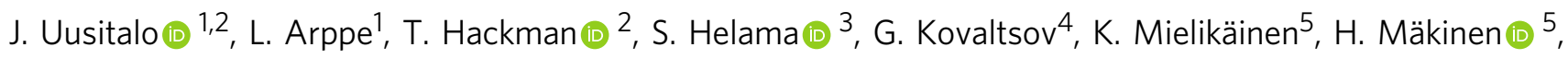
P. Nöjd ${ }^{5}$, V. Palonen ${ }^{2}$, I. Usoskin 6 \& M. Oinonen (ib ${ }^{1}$

Recently, a rapid increase in radiocarbon $\left({ }^{14} \mathrm{C}\right)$ was observed in Japanese tree rings at $A D$ 774/775. Various explanations for the anomaly have been offered, such as a supernova, a $\gamma^{-}$ ray burst, a cometary impact, or an exceptionally large Solar Particle Event (SPE). However, evidence of the origin and exact timing of the event remains incomplete. In particular, a key issue of latitudinal dependence of the ${ }^{14} \mathrm{C}$ intensity has not been addressed yet. Here, we show that the event was most likely caused by the Sun and occurred during the spring of $A D$ 774. Particularly, the event intensities from various locations show a strong correlation with the latitude, demonstrating a particle-induced ${ }^{14} \mathrm{C}$ poleward increase, in accord with the solar origin of the event. Furthermore, both annual ${ }^{14} \mathrm{C}$ data and carbon cycle modelling, and separate earlywood and latewood ${ }^{14} \mathrm{C}$ measurements, confine the photosynthetic carbon fixation to around the midsummer.

\footnotetext{
${ }^{1}$ Finnish Museum of Natural History, University of Helsinki, P.O. Box 64, 00014 Helsinki, Finland. ${ }^{2}$ Department of Physics, University of Helsinki, P.O. Box 64, 00014 Helsinki, Finland. ${ }^{3}$ Natural Resources Institute Finland, Eteläranta 55, 96300 Rovaniemi, Finland. ${ }^{4}$ Ioffe Physical-Technical Institute, 
R adiocarbon $\left({ }^{14} \mathrm{C}\right)$ is produced in the Earth's stratosphere/ troposphere mostly by thermal neutrons captured by nitrogen nuclei. Thermal neutrons are produced by nuclear reactions of high-energy cosmic rays, originating mainly from galactic sources, or to a smaller extent, from the Sun. ${ }^{14} \mathrm{C}$ oxidizes to $\mathrm{CO}_{2}$, and tropospheric $\mathrm{CO}_{2}$ is eventually stored in tree rings through $\mathrm{CO}_{2}$ fixation by photosynthesis during growing season. Rapid events producing ${ }^{14} \mathrm{C}$ are eventually reflected in tropospheric or tree-ring ${ }^{14} \mathrm{C}$ measurements as peaks with an abrupt increase and a long decrease of dozens of years caused by the exchange of ${ }^{14} \mathrm{C}$ between the atmosphere and Earth's carbon reservoirs. Such a ${ }^{14} \mathrm{C}$ increase was recently observed in Japanese tree rings by Miyake et al. ${ }^{1}$ from AD 774 to AD 775 (henceforth ME meaning Miyake event), followed by similar observations throughout Northern Hemisphere $(\mathrm{NH})^{2-6}$ and even in New Zealand ${ }^{7}$.

The shielding effect of the geomagnetic field against charged cosmic ray particles, i.e., the geomagnetic (vertical) cutoff rigidity $\left(R_{\mathrm{C}}\right)$ is the highest near the equator and decreases towards the polar regions. Therefore, particles producing cosmogenic nuclei most easily penetrate into the atmosphere at high geomagnetic latitudes ${ }^{8}$. In addition to stratospheric production, a fraction of ${ }^{14} \mathrm{C}$ can be formed in the troposphere allowing for rapid photosynthetic fixation.

The initial atmospheric ${ }^{14} \mathrm{C}$ pool is affected by carbon cycle dynamics. In addition to vertical transport, horizontal transport of ${ }^{14} \mathrm{C}$ within the atmosphere alters the local ${ }^{14} \mathrm{C}$ pool sampled by the trees. However, remnants of the original polar production and its latitudinal dependence may still be observed in the ${ }^{14} \mathrm{C}$ signal stored into tree rings by the photosynthetic assimilation, particularly due to tropospheric production of ${ }^{14} \mathrm{C}$. Indeed, such subtle latitudinal differences induced by the initial production and entangled with the carbon cycle dynamics have been observed by measuring the treering ${ }^{14} \mathrm{C}$ contents ${ }^{9,10}$. Assuming a solar origin for $\mathrm{ME}$, and thus initial ${ }^{14} \mathrm{C}$ production at polar latitudes, one may observe changes in the intensity of the anomaly according to the latitude.

Here, we report the measurement of annual ${ }^{14} \mathrm{C}$ content of a Finnish Lapland tree during the ME, so far closest to the contemporary Geomagnetic North Pole (GNP). By utilizing a peakfitting approach and complementing our results with previously published data, we find a latitudinal tendency in the event intensities, which is consistent with a solar origin. Furthermore, based on both carbon cycle modelling and additional earlywood (EW) and latewood (LW) ${ }^{14} \mathrm{C}$ tree-ring measurements, we find that the event occurred probably during the spring of AD 774.

\footnotetext{
Results

${ }^{14} \mathrm{C}$ intensities. For a strong Solar Particle Event (SPE), like that of 23 February 1956, the atmospheric production of ${ }^{14} \mathrm{C}$ can be orders of magnitude larger in polar regions compared to tropical latitudes, with high $R_{C}$ 's (Fig. 1). Hence, we hypothesize that the ${ }^{14} \mathrm{C}$ intensity induced by an ME has a latitudinal tendency if the event is of solar origin because $R_{\mathrm{C}}$ governs the number of solar particles that enter the Earth's atmosphere and the tropospheric production supports rapid photosynthetic fixation. The $R_{\mathrm{C}}$ values, calculated using the recent archaeomagnetic model AF_M ${ }^{11}$ (see Methods), for the epoch of AD 775 provide insight into the initial ${ }^{14} \mathrm{C}$ production rates according to locations (see Supplementary Table 1). The location of the GNP at AD $775\left(\mathrm{GNP}_{\mathrm{AD} 755}\right)$ can be estimated to be north-east from Svalbard at approximately $82^{\circ} \mathrm{N}$, $25^{\circ}$ E. In the vicinity of the $\mathrm{GNP}_{\mathrm{AD} 775}$, the modelled $R_{\mathrm{C}}$ approaches $0 \mathrm{GV}$, implying that even low-energy particles can impinge on the atmosphere. Suggested hard particle spectrum of $\mathrm{ME}^{12}$ would likely result in partial tropospheric production of ${ }^{14} \mathrm{C}$ (see Methods).
}

The hypothesis is tested by evaluating the significance of the latitudinal trend of the available ME data through Pearson's correlation. Our tree-ring material is derived from a precisely cross-dated 7600-year long Scots pine (Pinus sylvestris) record collected from Finnish Lapland ${ }^{13-15}$, in particular, from Lake Kompsiojärvi (68.5N, 28.1E; hereafter LAP). We complement our results with previously published and precisely cross-dated data from Yamal/Russia $\left(67.5^{\circ} \mathrm{N}, 70.7^{\circ} \mathrm{E} \text {; YAM }\right)^{3}$, Poland $\left(50.1^{\circ} \mathrm{N}\right.$, $20.1^{\circ} \mathrm{E}$; POL $)^{4}$, Germany $\left(50^{\circ} \mathrm{N}, 9^{\circ} \mathrm{E} \text {; GER }\right)^{2}$, Altai/Russia $\left(47.5^{\circ}\right.$ $\left.\mathrm{N}, 87.5^{\circ} \mathrm{E} ; \mathrm{ALT}\right)^{5}$, Japan $\left(30.4^{\circ} \mathrm{N}, 130^{\circ} \mathrm{E} \text {; JAP }\right)^{1}$, USA $\left(38.3^{\circ} \mathrm{N}\right.$, $118.7^{\circ} \mathrm{W} ; \mathrm{CAL}^{3}$ and $36.5^{\circ} \mathrm{N}, 118.8^{\circ} \mathrm{W}$; CAL2 ${ }^{6}$ ) and New Zealand $\left(36.0^{\circ} \mathrm{S}, 173.8^{\circ} \mathrm{E} ; \mathrm{NZL}\right)^{7}$ to analyze the latitudinal behaviour. The LAP and YAM locations are within $15^{\circ}$ of latitude from the $\mathrm{GNP}_{\mathrm{AD} 775}$. This close vicinity is reflected as low

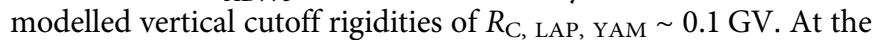
southern extreme of the locations (CAL1, CAL2, JAP), the values are very high $\left(R_{\mathrm{C}, \mathrm{CAL}}\right.$, JAP $\left.\sim 10 \mathrm{GV}\right)$, which should yield drastically lower initial atmospheric production of ${ }^{14} \mathrm{C}$, particularly in these locations (Fig. 1). We utilize peak-fitting analysis to extract the full ${ }^{14} \mathrm{C}$ intensities related to $\mathrm{ME}$ to acknowledge the temporal spread of tropospheric ${ }^{14} \mathrm{C}$ increase into several years (see Methods).

We observe a clear increase of ${ }^{14} \mathrm{C}$ content in subfossil tree rings from LAP (Fig. 2, Supplementary Table 3) corresponding to ME. Actually, the ${ }^{14} \mathrm{C}$ content is increased already during $\mathrm{AD} 774-$ it differs $5.3 \sigma$ from the averaged ${ }^{14} \mathrm{C}$ background of $\mathrm{AD} 770-773$. Interestingly, YAM also shows an increase during AD 774 with respect to its ${ }^{14} \mathrm{C}$ background. This increase is not statistically different from LAP ( $p=0.24$, Student's $t$-test) reflecting their small latitudinal separation. The deduced ${ }^{14} \mathrm{C}$ intensities $I_{14 \mathrm{C}}$ (see Methods, Supplementary Table 1) as a function of latitude are shown in Fig. 3. Our null hypothesis of a constant $I_{14 \mathrm{C}}($ slope $=0)$ as a function of latitude is rejected with a significance level of $p=$ 0.002 (Student's $t$-test). Thus, inarguably, there is a statistically significant latitudinal trend within the data. The relation between the latitude and ${ }^{14} \mathrm{C}$ intensity is supported by the high correlation of $r\left(\right.$ lat, $\left.I_{14 \mathrm{C}}\right)=0.87$. This latitudinal trend cannot be explained by a possible seasonal variation of the tropospheric ${ }^{14} \mathrm{C}$ concentration nor by differing growing season lengths. Although some seasonal variation may occur after an instant injection of ${ }^{14} \mathrm{C}$ into the atmosphere ${ }^{16}$, we found its role insignificant (see Supplementary Note 1). The observed trend is consistent with the higher production rate of ${ }^{14} \mathrm{C}$ at high latitudes and its redistribution within the atmosphere towards lower latitudes and into other carbon reservoirs. This finding implies a polar enhancement of the cosmogenic signal, which is also experimentally known for ${ }^{10} \mathrm{Be}$ in polar ice ${ }^{17}$. The enhancement is probably mediated partially by the direct tropospheric production of ${ }^{14} \mathrm{C}$. The polar enhancement shown here supports our hypothesis of a charged-particle-induced ${ }^{14} \mathrm{C}$ increase.

Interestingly, differences within the NH Zone 1 (NH1, Fig. 3) locations (LAP, YAM, POL, GER, ALT) are relatively small, although visible. However, there are larger differences between the intensities of $\mathrm{NH1}$ and non-NH1 locations (JAP, CAL1, CAL2, NZL). In fact, we see statistically significant $(p=0.008$, permutation test) difference between $\mathrm{NH} 1$ and non-NH1 zones (see Methods). This indicates similar atmospheric circulation patterns defining the ${ }^{14} \mathrm{C}$ spatial distributions for $\mathrm{ME}$ as for the bomb peak induced by atmospheric nuclear detonations in $\mathrm{NH}$, and probably reflects the locations in both sides of the tropospheric Ferrel cell-Hadley cell boundary ${ }^{18}$.

Origin of the event. The charged-particle flux cannot be due to Galactic Cosmic Rays (GCR) because they would not result in such a peaked ${ }^{14} \mathrm{C}$ distribution ${ }^{19}$. This is due to perturbation of 


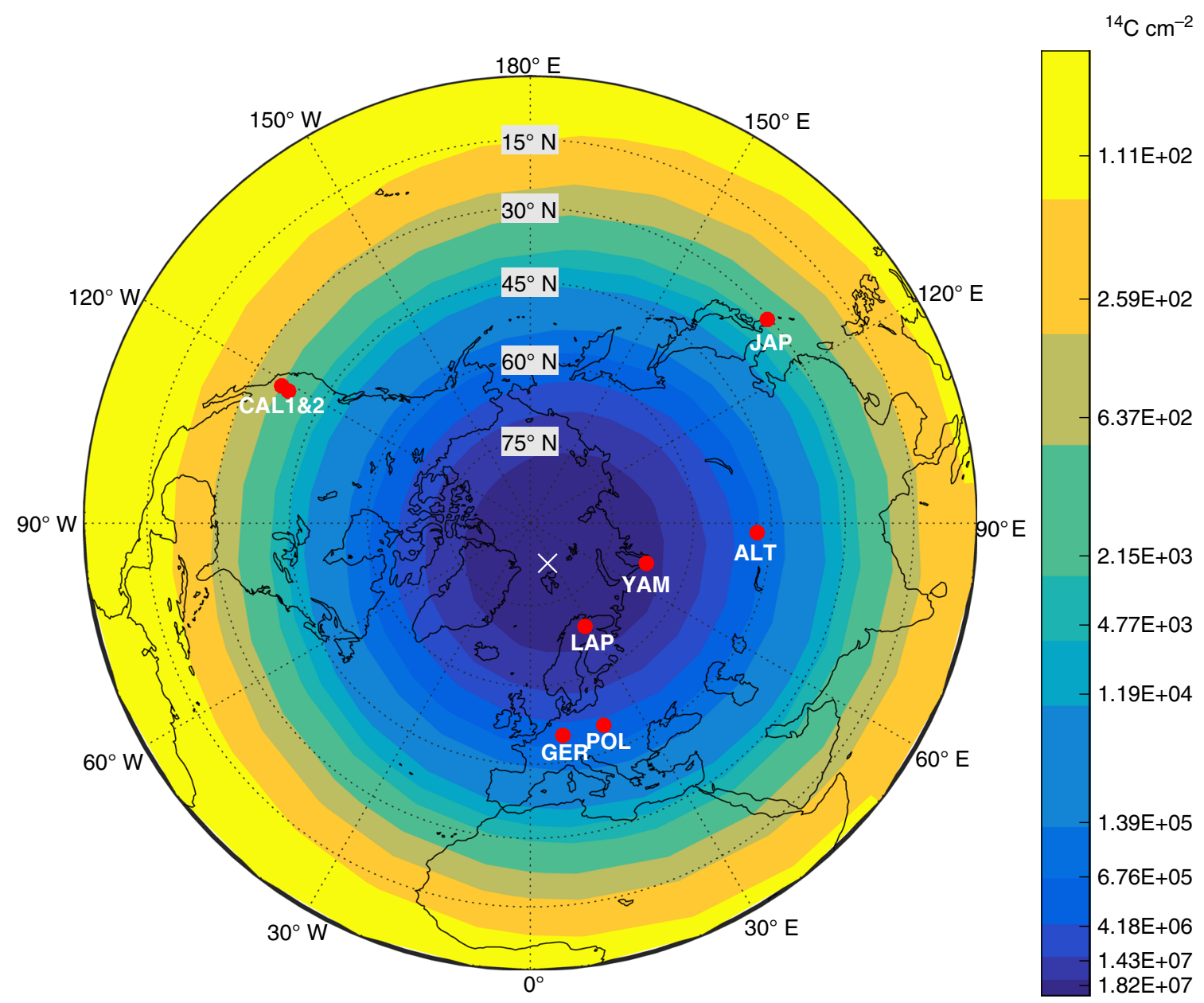

Fig. 1 Map of the study region. The colour codes show the latitudinal differences of ${ }^{14} \mathrm{C}$ production rate $\left({ }^{14} \mathrm{C} \mathrm{cm}^{-2}\right.$ ) for a typical strong SPE (such as 23 February 1956, the strongest directly observed event, Supplementary Table 2). The ${ }^{14} \mathrm{C}$ production model ${ }^{36}$ is described in the Methods section. The red full circles with three-letter coding show the measurement locations for ${ }^{14} \mathrm{C}$ intensities (see text). The cross illustrates the location of the Geomagnetic North Pole in AD 775

GCR by galactic magnetic fields during their travel to Earth causing dispersion and retardation. Moreover, GCR vary within the 11-year solar cycle due to the heliospheric modulation, which is too slow to produce a sharp peak. The observation also excludes the possibility of the increase being caused by supernova $\gamma$-rays ${ }^{1}$ or $\gamma$-ray bursts ${ }^{20,21}$ because they are not affected by the geomagnetic field and hence would not cause latitude-dependent effects. Furthermore, significant ${ }^{10} \mathrm{Be}$ signal linked to the ME was found in both Greenland and Antarctic ice cores ${ }^{12,22}$. In addition, the observed $I_{14 \mathrm{C}}$ of NZL (Fig. 3) is consistent with bipolarity. Such bipolar effects should not occur if the isotope production was confined to only one of the hemispheres. Recently, a cometary impact was suggested to explain the anomaly ${ }^{23}$. However, a comet could explain the observed latitude effects only if it disintegrated near the $\mathrm{GNP}_{\mathrm{AD} 775}$. Even then, it should not cause any signal in ${ }^{10} \mathrm{Be}$. Moreover, due to the required massive size, the comet would have caused dramatic consequences to the biosphere and would not have gone unnoticed ${ }^{24}$.

Recent observations by the Kepler space telescope have shed light on the occurrence rate of these superflares on solar-like stars $^{25,26}$. Maehara et al. ${ }^{27}$ analyzed the Kepler data with a high time resolution to also include shorter duration superflares. Their analysis suggests that the occurrence rate of solar flares with energies ranging from $10^{33} \mathrm{erg}$ to $10^{34} \mathrm{erg}$ are consistent with the ME. On the other hand, it is still unclear whether superflaring stars can be directly compared with the Sun ${ }^{28}$. The Sun's relatively low magnetic activity around the time of the ME could be seen as problematic for the solar explanation ${ }^{29}$. However, Kilpua et al. recently found that the most extreme geomagnetic storms do not correlate well with the overall solar activity ${ }^{30}$. Hence, based on our observations and the above-described arguments, we suggest the Sun to be the cause of the event, in agreement with the recent study of Mekhaldi et al. ${ }^{12}$ using multiple cosmogenic nuclide records.

Timing of the event. Dynamics of ${ }^{14} \mathrm{C}$ can be elucidated through atmospheric Brewer-Dobson circulation model. Stratospherically produced ${ }^{14} \mathrm{C}$ intrudes into troposphere preferentially at midlatitudes within residence times of 1-2 years whereas mixing of tropospherically produced ${ }^{14} \mathrm{C}$ occurs within months ${ }^{31}$. Therefore, the latter may contribute to the observed signal immediately, whereas the assumed mid-latitude intrusion of air from stratosphere to troposphere takes place over in a longer time-scale in shaping up the observed ${ }^{14} \mathrm{C}$ peak shape. Our adopted 11-box carbon cycle model (CCM, see Methods), accompanied with data on both growing season length and monthly thermal-time sums (TTS) (see Methods) to mimic the tree-ring ${ }^{14} \mathrm{C}$ contents, allows us to reproduce the experimentally observed ${ }^{14} \mathrm{C}$ peak shape generally with high correlation. Therefore, we argue that our CCM, although not containing the horizontal carbon cycle dynamics, provides us a reasonable tool to evaluate the event 


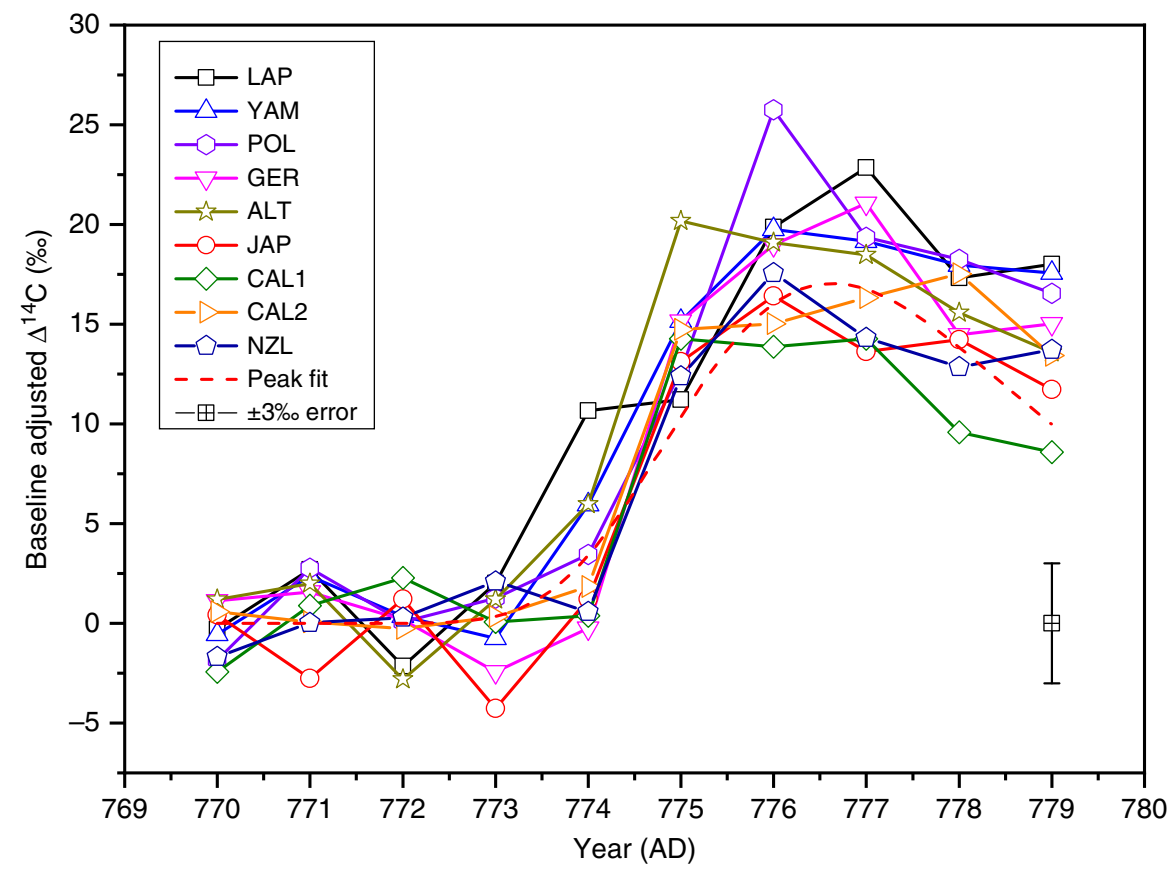

Fig. $2{ }^{14} \mathrm{C}$ measurements of the ME from multiple locations (see main text above for abbreviations). The horizontal axis represents the calendar year of the growing season, and the vertical axis represents the age-corrected and baseline-adjusted $\Delta^{14} \mathrm{C}$ (see Methods, Supplementary Table 3). The baseline adjustment has been performed for easier comparison of the data. The dashed red line shows an example of the analytical type I Gumbel distribution function (GDF) fit to the JAP data. Each measurement has a standard error of typically $\pm 3 \%$ as visualized in the lower right corner. Original intensities, uncertainties and fitting procedure are as described in the Methods section

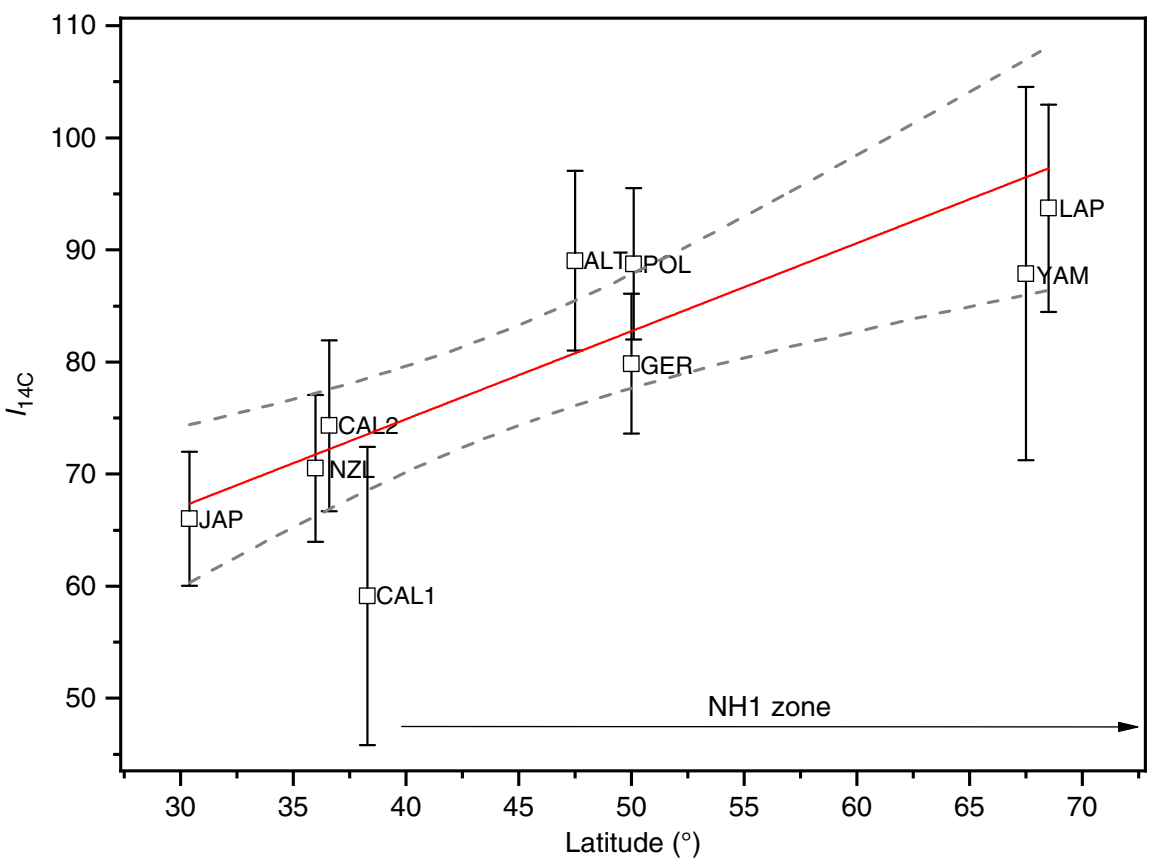

Fig. 3 Latitude vs. the ${ }^{14} \mathrm{C}$ intensity $I_{14 \mathrm{C}}$. The red line is a linear fit to the data. The uncertainties are based on error propagation and represent one standard error, and the dashed lines indicate the $95 \%$ confident intervals for the fit. The ${ }^{14} \mathrm{C}$ intensities are obtained by fitting a GDF with each data set and by defining the $I_{14 \mathrm{C}}$ as an integral of this curve (see Methods). $\mathrm{NH} 1$ zone has been adopted from Hua et al. ${ }^{18}$. Differences in the ${ }^{14} \mathrm{C}$ spatial distribution are manifested by distinct zones that span through both hemispheres, latitudes North of $40^{\circ} \mathrm{N}\left(\mathrm{NH} 1\right.$ zone) having the highest bomb-peak ${ }^{14} \mathrm{C}$ intensities

timing, motivated by the observation of ${ }^{14} \mathrm{C}$ increase in LAP already at AD 774.

The LAP site is closest to the polar origin of the chargedparticle induced ${ }^{14} \mathrm{C}$ production. Furthermore, for $P$. sylvestris, carbon isotope signals of fresh photosynthates and tree-ring cellulose correlate strongly, indicating rapid transfer of atmospheric carbon into tree stem $^{32}$. Therefore, Arctic trees of LAP are presumably able to rapidly record the assumed partial tropospheric production. In addition, the short growing season should sensitively probe the ME timing. We define the ME timing as the 


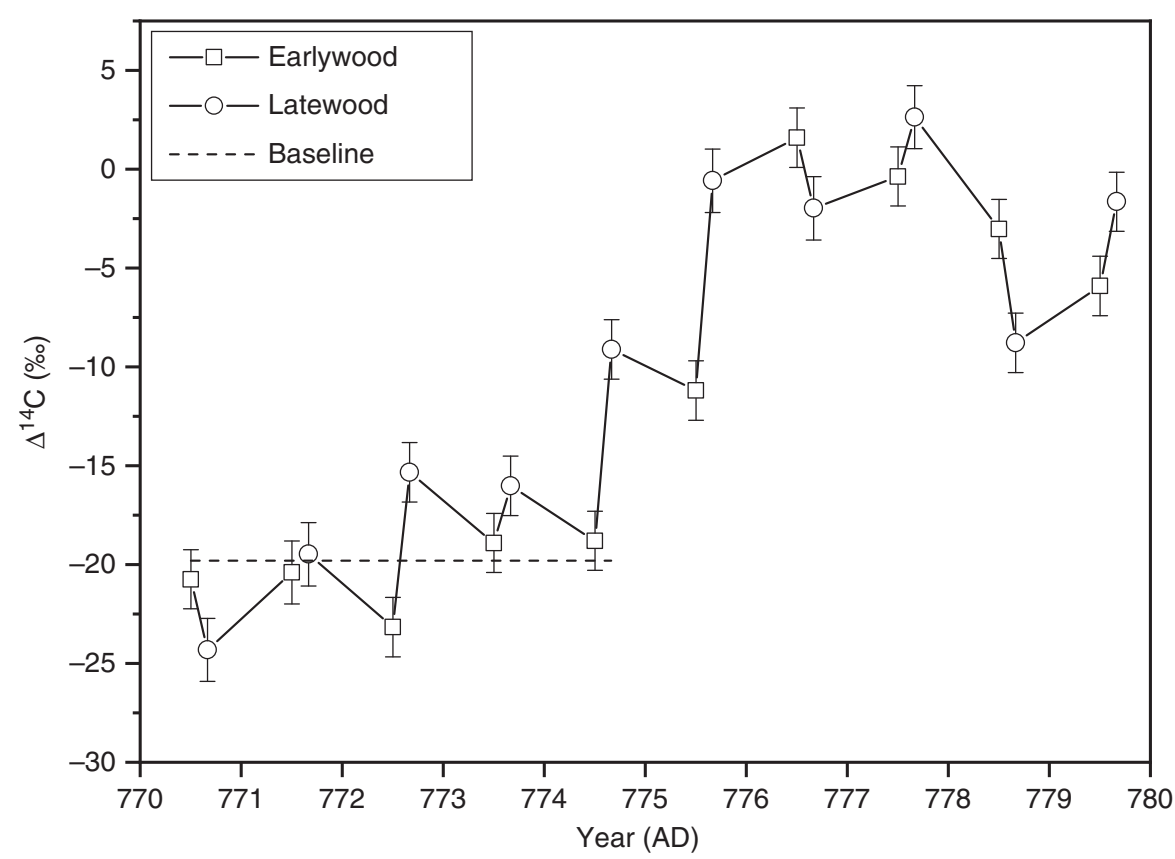

Fig. 4 Early- and latewood ${ }^{14} \mathrm{C}$ measurements of the ME. The horizontal axis represents the calendar year of the growing season, and the vertical axis represents the age-corrected $\Delta^{14} \mathrm{C}$. To visualize the average temporal difference between early- and latewood growth, the data points are set to June and August, respectively, for each calendar year. The baseline is defined as the average ${ }^{14} \mathrm{C}$ of $\mathrm{AD} 770-773$. The uncertainties are based on ${ }^{14} \mathrm{C}$ counting statistic and error propagation and they represent one standard error

moment when the tropospherically produced ${ }^{14} \mathrm{C}$ has oxidized to ${ }^{14} \mathrm{CO}_{2}$ being thus available for photosynthesis (see Methods). We modelled the tropospheric ${ }^{14} \mathrm{C}$ increases using different $\mathrm{ME}$ timings and compared those to the yearly data of LAP to obtain the best match. Based on Mekhaldi et al. ${ }^{12}$ and in line with Usoskin et al. ${ }^{2}$, we assumed a hard spectrum for the SPE with $70 \%$ of the ${ }^{14} \mathrm{C}$ produced in the stratosphere and $30 \%$ in the troposphere (see Methods). The lowest residual sum of squares (RSS) between the measured and modelled data was observed assuming the ME timing during June/AD 774 (see Methods). Hence, a midsummer timing is implicated. Differing assumed tropopause height profiles can probably result in systematic shifts up to few months, particularly towards spring (see Supplementary Note 2).

The thermal growing season in LAP extends from May to September (see Methods). The EW to LW transition for $P$. sylvestris at these latitudes occurs typically around mid-July ${ }^{33}$, which is close to the ME timing indicated above. Therefore, assuming the ME timing around midsummer in $\mathrm{AD} 774$, only the LW ${ }^{14} \mathrm{C}$ content should be elevated in the cellulose formed in $\mathrm{AD}$ 774. We tested this hypothesis by EW-LW measurements (Fig. 4) to confirm the ME timing. As expected, both EW and LW data show the similar peak shape as the annual LAP data (Fig. 2), consistent also in magnitude. However, only LW shows a significant $(7.1 \sigma)$ increase of the ${ }^{14} \mathrm{C}$ content in $\mathrm{AD} 774$, in accord with our expectations. During AD 772, the EW ring width is exceptionally wide (Supplementary Table 3). Therefore, the annual ${ }^{14} \mathrm{C}$ signal resembles that of $\mathrm{EW}_{\mathrm{AD} 772}$. Based on large $\mathrm{EW} /$ LW ring width ratio, similar mechanism may also be seen in $\mathrm{AD}$ 775. Differences between annual and EW/LW signals will be addressed in forthcoming papers based on stable isotopic and ${ }^{14} \mathrm{C}$ analyses.

Based on above, the observed ${ }^{14} \mathrm{C}$ increase in $\mathrm{LW}_{\mathrm{AD} 774}$ is consistent with our annual data and confirms our model-based result of the event timing. Altogether, observing elevated ${ }^{14} \mathrm{C}$ content in $\mathrm{LW}_{\mathrm{AD} 774}$ and not observing it in $\mathrm{EW}_{\mathrm{AD} 774}$ confines the event timing probably to the advent of the boreal midsummer in
$\mathrm{AD}$ 774. It allowed for the produced ${ }^{14} \mathrm{C}$ to be photosynthetically fixed during the late growing season of $P$. sylvestris in Finnish Lapland. This $\mathrm{NH}$ observation is in contrast with the one from the Southern Hemisphere, for which an event timing of spring/ $\mathrm{AD} 775$ has been proposed ${ }^{7}$, but is in agreement with estimations based on ${ }^{10} \mathrm{Be}$ data of $\mathrm{AD} 774$ occurrence ${ }^{34}$. Taking into account the uncertainties in the tropopause height profile and the assumed average atmospheric oxidation time of ${ }^{14} \mathrm{C}$ of 1-2 months ${ }^{35}$, the solar event itself occurred few months earlier.

\section{Discussion}

In summary, the ME has been observed in tree-rings of $P$. sylvestris from Finnish Lapland, so far closest to the GNP of AD 775. This has allowed us to demonstrate a latitudinal trend within the available data sets. By utilizing a peak-fitting approach, we find strong correlation between the latitude and determined ${ }^{14} \mathrm{C}$ intensities. This is consistent with the assumed solar origin of the event. The timing is confirmed by sub-annual measurements of tree-ring cellulose showing anomalous increase of the ${ }^{14} \mathrm{C}$ content in the LW of AD 774. This study illustrates the importance of trees growing near the boreal tree limit for storing information regarding both space weather and atmospheric circulation patterns.

\section{Methods}

${ }^{14} \mathrm{C}$ production due to an SPE. The production of ${ }^{14} \mathrm{C}$ was calculated using the new-generation model ${ }^{36}$, which simulates, using a full Monte-Carlo technique, nucleonic cascade induced by cosmic rays in the Earth's atmosphere and yields a $3 \mathrm{D}$ distribution of the ${ }^{14} \mathrm{C}$ production. The spectrum of energetic particles for the event was considered hard ${ }^{2,12}$. The geomagnetic field was considered according to the archaeomagnetic model by Licht et al. ${ }^{11}$.

As an estimate of the tropospheric production, we applied a flat mean tropopause at the height of $150 \mathrm{hPa}$ (cf. Usoskin et al. ${ }^{2}$ ) and found that about $30 \%$ of polar ${ }^{14} \mathrm{C}$ is produced in the troposphere, for a hard-spectrum SPE. We note that globally about half of ${ }^{14} \mathrm{C}$ is produced in the troposphere for such event. However, the flat-troposphere assumption may not exactly hold for the polar region, where the tropopause is typically lower, at the $200-300 \mathrm{hPa}$ barometric pressure level, leading to a lower tropospheric production. When applying a local height profile of the polar tropopause $\mathrm{s}^{37,38}$, we found that the fraction of tropospheric production of 
${ }^{14} \mathrm{C}$ in the polar region is about $15 \%$. Accordingly, we used this range as an uncertainty and translated it into the uncertainty of the event's date derivation.

The map of the study region (Fig. 1) was created using Matlab R2016b software (https://www.mathworks.com/). Specifically, the $R_{\mathrm{C}}$ values from Supplementary Fig. 1 and the respective ${ }^{14} \mathrm{C}$ production values from Supplementary Table 2 were used to define the differently coloured regions. The GNP and the measurement locations are given in Supplementary Table 1. The data and the code to reproduce the figure can be obtained from the authors.

Estimation of vertical cutoff rigidities. Although the ME took place well before the era of direct geomagnetic measurements, we are able to assess the geomagnetic cutoff rigidities at different locations for the period relying on precise archaeomagnetic reconstructions. These are based on measurements of the archaeologically dated clay samples preserving the local magnetic intensity during the time of their firing. Since the eighth century was rich for archaeological artefacts, the quality of geomagnetic field reconstructions is reasonable for that period.

Here we use the AF $M$ archaeomagnetic reconstruction model ${ }^{11}$, which is provided as an ensemble of 1000 individual reconstructions of the geomagnetic field with a pseudo annual resolution. The ensemble naturally covers all the sources of uncertainties of the reconstruction (measurement errors, sample size, systematic errors, model uncertainties).

For each of the individual ensemble member reconstructions we calculated, for a given location, the geomagnetic cutoff rigidity $R_{\mathrm{C}}$, using the eccentric dipole approximation of the field, based on the first eight Gaussian spherical coefficients (see full details in the Appendix A of Usoskin et al. ${ }^{39}$ ). The mean $R_{\mathrm{C}}$, and its standard deviation, was finally calculated from the obtained 1000 values of individual $R_{C}$ s over the ensemble, as shown in Supplementary Table 1.

We choose the AF_M model because it provides a full ensemble to assess the error bars and the Gaussian coefficients, and this result is consistent, within the shown uncertainties, with the geomagnetic dipole moment provided by other recent archeomagnetic reconstructions for the period of AD $775^{36,40-44}$.

In the same way, we calculated a map of the $R_{\mathrm{C}}$ values for the $\mathrm{AD} 775$ epoch (Supplementary Fig. 1), using the mean $R_{\mathrm{C}}$ values.

Tree-ring and radiocarbon analyses. A subfossil sample with well discernible rings over the study period was chosen for this analysis. The sample was tree-ring dated using statistical routines ${ }^{45}$ and visually by comparing the series of its ring widths against those of the master chronology ${ }^{14}$. The widths of the annual rings were on average $0.49 \mathrm{~mm}$, with maximum and minimum widths of 0.73 and 0.37 $\mathrm{mm}$, respectively. The sampling was done using a sterile surgical blade under the light microscope. No cross-contamination from one ring to the next was allowed by visual inspection. The separation of the EW and LW of the same calendar year was based on the intra-annual cellular characteristics discernible on the crosssectional surface of the sample, generally following the established criteria ${ }^{46}$. In tree-ring laboratory, all the work to extract the isotope samples was done on cleaned sample surfaces to minimize any potential external contamination.

Tree-ring dated wood slivers were processed to a-cellulose using the batch approach designed by Wieloch et al. ${ }^{47}$. The process consists of two alkaline extractions $(5-7 \% \mathrm{NaOH})$, with a chlorination step $\left(\mathrm{NaClO}_{2}\right)$ in between. The resulting $\alpha$-cellulose was homogenized using an ultrasonic probe ${ }^{48}$ and freezedried. Pretreated samples were mixed with a stoichiometric excess of $\mathrm{CuO}$ and packed into quartz ampoules, which were evacuated and torch-sealed. The packed samples were combusted at $850^{\circ} \mathrm{C}$ overnight. The released $\mathrm{CO}_{2}$ was collected and purified with liquid $\mathrm{N}_{2}$ and ethanol traps at -196 and $-85^{\circ} \mathrm{C}$, respectively. The $\mathrm{CO}_{2}$ samples were converted to graphite targets ${ }^{49}$ for AMS radiocarbon measurements. AMS measurements were eventually performed at the University of Helsinki AMS facility ${ }^{50}$. The results are given as age-corrected $\Delta^{14} \mathrm{C}$ values ${ }^{51}$. For more detailed description of the analyses, see Helama et al..$^{52}$.

Peak analysis procedure and fittings. Stratospheric mean residence times of ${ }^{14} \mathrm{C}$ are typically $1-2$ years. Therefore, it can be estimated that after, say 3 years, $5-22 \%$ of ${ }^{14} \mathrm{C}$ remains still in stratosphere. Thus, stratosphere supplies new ${ }^{14} \mathrm{C}$ into troposphere, and therefore for photosynthesis, several years after an abrupt event. Peak-fitting approach was chosen since it allows for quantifying the peak shape by taking into account all the available information, namely the data and its uncertainties, during the time span of this ${ }^{14} \mathrm{C}$ supply. In addition, our approach takes into account the possible laboratory biases caused by slightly different pretreatment procedures. These biases are typically systematic and could cause some differences in the observed baseline levels. Our method helps to mitigate this effect, since it takes into account the respective baseline of the data. Furthermore, the full peak shape contains also information on possible use of formed year photosynthetic storages.

We fitted a Type-1 Gumbel distribution function (GDF) to each of the data. The GDF has the following form:

$$
y=y_{0}+A \mathrm{e}^{\left(-\mathrm{e}^{\left(-\frac{x-x_{\mathrm{c}}}{w}\right)}-\frac{x-x_{\mathrm{c}}}{w}+1\right)},
$$

where $y_{0}$ is the baseline level (also used when adjusting the peaks to zero baseline), $A$ is the amplitude of the peak, $x_{\mathrm{c}}$ is the time of the peak maximum and $w$ is the width of the peak. GDF is normally used in extreme event statistics ${ }^{53}$ and its shape is characterized by a rapid rise and an exponential tail. Therefore, it is suitable for deducing intensities of rapidly increasing and slowly decreasing events occurring together with a relatively constant background, such as ${ }^{14} \mathrm{C}$ intensity increase due to an SPE. Other distributions with similar shapes, such as Log-Normal and Exponentially Modified Gaussian that are often used in peak analysis ${ }^{54}$ were also considered, but GDF was found to be superior because of its overall convenience of use, simplicity of equation and property to not over-fit to statistical noise.

Furthermore, GDF has been used before in peak analyses in a similar fashion to what is done here ${ }^{55}$. The GDF fit to each of the ME measurement can be seen in Supplementary Figs 3-10. Additionally, Supplementary Fig. 11 shows a GDF fit to a typical $\Delta^{14} \mathrm{C}$ profile due to instant injection of ${ }^{14} \mathrm{C}$ into the atmosphere modelled by our adopted CCM.

To get the peak intensities, we analytically integrate the GDF in Eq. (1), which then becomes

$$
y=\int A \mathrm{e}^{\left(-\mathrm{e}^{\left(-\frac{x-x_{\mathrm{c}}}{w}\right)}-\frac{x-x_{\mathrm{c}}}{w}+1\right)} \mathrm{d} x=A w \mathrm{e}^{\left(1-\mathrm{e}^{\left(\frac{x_{\mathrm{c}}-x}{w}\right)}\right)}+C .
$$

The interval used to calculate the integral for each of the data sets is bound to be from 770 to 779 . The interval was chosen since it covers the event occurrence and the tropospheric near-event time distribution of ${ }^{14} \mathrm{C}$ but not the long tail influenced merely by carbon cycle characteristics. Thus, the equation for the ${ }^{14} \mathrm{C}$ intensity $I_{14 \mathrm{C}}$ becomes

$$
I_{14 \mathrm{C}}=\int_{770}^{779} A \mathrm{e}^{\left(-\mathrm{e}^{\left(-\frac{x-x_{c}}{w}\right)}-\frac{x-x_{c}}{w}+1\right)} \mathrm{d} x=A w \mathrm{e}^{\left(1-\mathrm{e}^{\left(\frac{x_{c}-779}{w}\right)}\right)}-A w \mathrm{e}^{\left(1-\mathrm{e}^{\left(\frac{x_{c}-770}{w}\right)}\right)} .
$$

In addition, an error estimate $\sigma$ of the $I_{14 \mathrm{C}}$ is calculated. This is done by propagating errors for the known values of $A, x_{\mathfrak{c}}, w$ and their standard errors in Eq. (3). The integrated ${ }^{14} \mathrm{C}$ intensities can be seen in Supplementary Table 1.

To be confident on the capability of the peak-fitting method to capture the underlying ${ }^{14} \mathrm{C}$ intensity, we tested our method by comparing simulated and peakfitted peak sizes to the theoretically expected ones (Supplementary Fig. 2). The CCM provides a theoretically expected ${ }^{14} \mathrm{C}$ intensity (red line in Supplementary Fig. 2) based on the underlying ${ }^{14} \mathrm{C}$ production. The Monte Carlo simulation provides ${ }^{14} \mathrm{C}$ peaks ( $10^{5}$ runs) for each underlying ${ }^{14} \mathrm{C}$ intensity by assuming $3 \%$ statistical measurement errors. These were peak-fitted individually to obtain simulated ${ }^{14} \mathrm{C}$ intensities (open squares in Supplementary Fig. 2). This sensitivity analysis demonstrated that the peak-fitting method captures the underlying relative ${ }^{14} \mathrm{C}$ intensities extremely well. Hence, the peak-fitting method can be considered robust.

${ }^{14} \mathrm{C}$ intensities in NH1 and non-NH1 zones. Atmospheric ${ }^{14} \mathrm{C}$ analyses based on bomb peak have demonstrated distinct zones of varying ${ }^{14} \mathrm{C}$ contents within the $\mathrm{NH}^{18}$. These are related to the observed circulation cells within the atmosphere. Visually, the ${ }^{14} \mathrm{C}$ intensities of $\mathrm{NH} 1$ and non-NH1 zones for ME seem to form two latitudinally separate groups (Fig. 3). We tested whether this difference is statistically meaningful. Because the individual ${ }^{14} \mathrm{C}$ intensities do not necessarily follow a normal distribution, we could not use Student's $t$-test or any other test that assumes normality. Hence, we used a resampling method to perform an exact significance test. Specifically, this was done as follows. First, we calculated the test statistic (e.g., difference of means) using groups $\mathrm{NH1}$ and non-NH1. Second, we combined the values of $\mathrm{NH} 1$ and non-NH1 into a single pool. Third, we performed a Monte Carlo simulation ( $10^{5}$ runs) where we randomly recombined these values into two groups with sizes of NH1 (5) and non-NH1 (4) groups. Fourth, we calculated the probability ( $p$-value) of finding values more extreme than our test statistic. The above analysis was performed using both the "difference of means between group 1 and group2" and the "sum of variances of group1 and group2" as test statistics. In both cases, the probability of finding value as extreme or more extreme than our test statistic is $p=0.008$. This analysis shows it is unlikely that the observed ${ }^{14} \mathrm{C}$ intensities of $\mathrm{NH} 1$ and non-NH1 groups originate from the same probability distribution, thus indicating latitudinal differences.

Carbon cycle model. We adopted a 11-box CCM from Güttler et al. ${ }^{7}$. Their model has an advantage of having a resolution of 1 month instead of 1 year used in most studies regarding the ME. Hence, it is especially suitable in assessing the timing of the event.

The carbon reservoir masses (a unit corresponds to $10^{12} \mathrm{~kg}$ ) and the annual fluxes $\left(10^{12} \mathrm{~kg} \mathrm{yr}^{-1}\right)$ between them can be seen in Supplementary Fig. 12. A mean atmospheric ${ }^{14} \mathrm{C}$ production rate of $1.88{ }^{14} \mathrm{C} \mathrm{cm}^{-2} \mathrm{~s}^{-1}$ atoms, which corresponds to an excess of $7.0 \mathrm{~kg} \mathrm{yr}^{-1}$, was used to obtain the atmospheric ${ }^{14} \mathrm{C}$ concentrations at around $\mathrm{AD}$ 775. In our model runs, we assume an event production rate of 83 ${ }^{14} \mathrm{C} \mathrm{cm}^{-2} \mathrm{~s}^{-1}$ over 1 month totalling to $25.8 \mathrm{~kg}$ of ${ }^{14} \mathrm{C}$. Seventy percent of the total ${ }^{14} \mathrm{C}$ production is assumed to have taken place in the stratosphere and $30 \%$ in the troposphere, which is also in line with Usoskin et al. ${ }^{2}$.

The model assumes that the ${ }^{14} \mathrm{C}$ is in the form of ${ }^{14} \mathrm{CO}_{2}$, which is not true immediately after the ${ }^{14} \mathrm{C}$ production. Although ${ }^{14} \mathrm{CO}$ is formed very rapidly, the 
mean oxidation time $\tau$ for ${ }^{14} \mathrm{CO}$ is approximately $1-2$ months ${ }^{35}$. Since oxidation is a statistical process, some ${ }^{14} \mathrm{CO}$ molecules get oxidized almost immediately, whereas it takes a long time for all the molecules to be oxidized. The rate of oxidation can be calculated using the exponential decay equation $N(t)=1-\mathrm{e}^{-\frac{t}{t}}$, where $t$ is the elapsed time and $\tau$ is the mean oxidation time. Assuming $t=\tau=$ 2 months, we find that $1-\frac{1}{e}(\sim 2 / 3)$ of the initially produced ${ }^{14} \mathrm{C}$ has oxidized to ${ }^{14} \mathrm{CO}_{2}$. Hence, we define our use of word timing to mean the moment, when $1-\frac{1}{\mathrm{e}}$ of the originally produced ${ }^{14} \mathrm{C}$ has oxidized to ${ }^{14} \mathrm{CO}_{2}$. In addition to being compatible with the model output, this definition is compatible with tree-ring measurements, since most of the original ${ }^{14} \mathrm{C}$ is in a form that can be photosynthetically sampled by trees. However, it is noted that the non-zero mean oxidation time adds up to 2 months systematic uncertainty as to when the initial ${ }^{14} \mathrm{C}$ production occurred.

Growing seasons and TTS. To estimate whether the climate around AD 775 was different from the modern era, we made a comparison between (a) the year $\mathrm{AD}$ 1959-2015 average $T_{\text {July }}$ (Finnish Meteorological Institute data, http://en. ilmatieteenlaitos.fi/open-data-manual) for Inari (68.9N, 27.0E) and (b) the treering width-based reconstructed temperatures of Finnish Lapland during $\mathrm{AD}$ $750-800^{56}$. The averages were $T_{\text {July } 1959-2015}=13.7 \pm 1.8^{\circ} \mathrm{C}$ and $T_{\text {July, rec } 750-800}=$ $13.1 \pm 0.9^{\circ} \mathrm{C}$. These values are identical within the uncertainties. Thus, we assumed similarity of the climate and thus the growing seasons for the era of the ME and of modern times.

To mimic the actual tree growth mediated by photosynthetic assimilation during the growing season within our model, we took into account the average ( $\mathrm{AD}$ 1959-2015 from Inari) TTS and weighted the monthly ${ }^{14} \mathrm{C}$ concentration (given by the model) by monthly fractions of TTS to obtain the peak shape in tree rings. These values can be seen in Supplementary Fig. 13.

Timing of the event by carbon cycle modelling. To estimate the timeframe for the event occurrence, we analyzed the data of the northernmost location LAP in more detail. The adopted CCM reproduces reasonably well the observed individual ${ }^{14} \mathrm{C}$ peak shapes (Supplementary Figs. 3-10). Moreover, we can reproduce the observed changes in the ${ }^{14} \mathrm{C}$ intensities with the model. Therefore, we adopted the modelled peak shape also for comparison to estimate the timeframe of the event. We weighted the modelled tropospheric ${ }^{14} \mathrm{C}$ content within the assumed growing season by monthly TTS to get an average ${ }^{14} \mathrm{C}$ content of tree rings for each year (AD 770-779). These modelled data, assuming different occurrence times of the event with a monthly resolution, were then compared with the measured data to find the lowest RSS, which is defined as follows:

$$
\mathrm{RSS}=\sum_{i=1}^{n}\left(y_{i}-f\left(x_{i}\right)\right)^{2},
$$

where $y_{i}$ is the measured $\Delta^{14} \mathrm{C}$ and $f\left(x_{i}\right)$ is the modelled $\Delta^{14} \mathrm{C}$ for each year through 770-779. These RSS values can be seen in Supplementary Fig. 14.

Data Availability. The data that support the findings of this study are available from the corresponding author upon reasonable request.

Received: 22 March 2018 Accepted: 30 July 2018

Published online: 28 August 2018

\section{References}

1. Miyake, F., Nagaya, K., Masuda, K. \& Nakamura, T. A signature of cosmic-ray increase in AD 774-775 from tree rings in Japan. Nature 486, 240-242 (2012).

2. Usoskin, I. G. et al. The AD775 cosmic event revisited: the Sun is to blame. Astron. Astrophys. Lett. 552, L3 (2013).

3. Jull, A. J. T. et al. Excursions in the 14C record at A.D. 774-775 in tree rings from Russia and America. Geophys. Res. Lett. 41, 3004-3010 (2014).

4. Rakowski, A. Z. et al. Increase of radiocarbon concentration in tree rings from Kujawy (SE Poland) around AD 774-775. Nucl. Instrum. Methods Phys. Res. B 361, 564-568 (2015).

5. Büntgen, U. et al. Cooling and societal change during the Late Antique Little Ice Age from 536 to around 660 AD. Nat. Geosci. 9, 231-236 (2016).

6. Park, J., Southon, J., Fahrni, S., Creasman, P. P. \& Mewaldt, R. Relationship between solar activity and $\triangle 14 \mathrm{C}$ peaks in AD 775, AD 994, and $660 \mathrm{BC}$. Radiocarbon 59, 1147-1156 (2017).

7. Güttler, D. et al. Rapid increase in cosmogenic $14 \mathrm{C}$ in $\mathrm{AD} 775$ measured in New Zealand kauri trees indicates short-lived increase in $14 \mathrm{C}$ production spanning both hemispheres. Earth Planet. Sci. Lett. 411, 290-297 (2015).

8. Masarik, J. \& Beer, J. An updated simulation of particle fluxes and cosmogenic nuclide production in the Earth's atmosphere. J. Geophys. Res. 114, D11103 (2009).
9. Grootes, P. M. Subtle ${ }^{14} \mathrm{C}$ signals: the influence of atmospheric mixing, growing season and in-situ production. Radiocarbon 34, 219-225 (1992).

10. Stuiver, M. \& Braziunas, T. F. Anthropogenic and solar components of hemispheric 14C. Geophys. Res. Lett. 25, 329-332 (1998).

11. Licht, A., Hulot, G., Gallet, Y. \& Thébault, E. Ensembles of low degree archeomagnetic field models for the past three millennia. Phys. Earth Planet. Inter. 224, 38-67 (2013).

12. Mekhaldi, F. et al. Multiradionuclide evidence for the solar origin of the cosmic-ray events of AD 774/5 and 993/4. Nat. Commun. 6, 8611 (2015).

13. Eronen, M., Hyvärinen, H. \& Zetterberg, P. Holocene humidity changes in northern Finnish Lapland inferred from lake sediments and submerged Scots pines dated by tree-rings. Holocene 9, 569-580 (1999).

14. Eronen, M. et al. The supra-long Scots pine tree-ring record for Finnish Lapland: part 1, chronology construction and initial inferences. Holocene 12, 673-680 (2002).

15. Helama, S., Mielikäinen, K., Timonen, M. \& Eronen, M. Finnish supra-long tree-ring chronology extended to 5634 BC. Nor. J. Geogr. 62, 271-277 (2008).

16. Randerson, J. T. et al. Seasonal and latitudinal variability of troposphere D14CO2: post bomb contributions from fossil fuels, oceans, the stratosphere, and the terrestrial biosphere. Global Biogeochem. Cycles 16, 1-19 (2002).

17. Bard, E., Raisbeck, G. M., Yiou, F. \& Jouzel, J. Solar modulation of cosmogenic nuclide production over the last millennium: comparison between $14 \mathrm{C}$ and 10Be records. Earth Planet. Sci. Lett. 150, 453-462 (1997).

18. Hua, Q., Barbetti, M. \& Rakowski, A. Z. Atmospheric radiocarbon for the period 1950-2010. Radiocarbon 55, 2059-2072 (2013).

19. Dee, $M$. et al. Supernovae and single-year anomalies in the atmospheric radiocarbon record. Radiocarbon 59, 293-302 (2016).

20. Hambaryan, V. V. \& Neuhäuser, R. A Galactic short gamma-ray burst as cause for the 14C peak in AD 774/5. Mon. Notices Royal Astron. Soc. 430, 32-36 (2013)

21. Pavlov, A. K. et al. Gamma-ray bursts and the production of cosmogenic radionuclides in the Earth's atmosphere. Astron. Lett. 39, 571-577 (2013).

22. Sigl, M. et al. Timing and climate forcing of volcanic eruptions for the past 2,500 years. Nature 523, 543-549 (2015).

23. Liu, Y. et al. Mysterious abrupt carbon-14 increase in coral contributed by a comet. Sci. Rep. 4, 3728 (2014).

24. Usoskin, I. G. \& Kovaltsov, G. A. The carbon-14 spike in the 8th century was not caused by a cometary impact on Earth. Icarus 260, 475-476 (2015).

25. Shibayama, T. et al. Superflares on solar type stars observed with Kepler I. Statistical properties of superflares. Astrophys. J. Suppl. Ser. 209, 5 (2013).

26. Wu, C.-J., Ip, W.-H. \& Huang, L.-C. A study of variability in the frequency distributions of the superflares of G-type stars observed by the Kepler mission. Astrophys. J. 798, 92 (2014).

27. Maehara, H. et al. Statistical properties of superflares on solar-type stars based on 1-min cadence data. Earth, Planets Space 67, 59 (2015).

28. Kitchatinov, L. L. \& Olemskoy, S. V. Dynamo model for grand maxima of solar activity: can superflares occur on the Sun? MNRAS 459, 4353-4359 (2016).

29. Cliver, E. W., Tylka, A. J., Dietrich, W. F. \& Ling, A. G. On a solar origin for the cosmogenic nuclide event of 775 A.D. Astrophys. J. 781, 32 (2014).

30. Kilpua, E. K. J. et al. Statistical study of strong and extreme geomagnetic disturbances and solar cycle characteristics. Astrophys. J. 806, 272 (2015).

31. Jacob, D. J. Introduction to Atmospheric Chemistry (Princeton University Press, Princeton, NJ, 1999).

32. Gessler, A. et al. Tracing carbon and oxygen isotope signals from newly assimilated sugars in the leaves to the tree-ring archive. Plant Cell Environ. 32, 780-795 (2009).

33. Schmitt, U., Jalkanen, R. \& Eckstein, D. Cambium dynamics of Pinus sylvestris and Betula spp. in the northern boreal forest in Finland. Silva Fenn. 38, 167-178 (2004).

34. Sukhodolov, T. et al. Atmospheric impacts of the strongest known solar particle storm of 775 AD. Sci. Rep. 7, 45257 (2017).

35. Weinstock, B. Carbon monoxide: residence time in the atmosphere. Science 166, 224-225 (1969).

36. Poluianov, S. V., Kovaltsov, G. A., Mishev, A. L. \& Usoskin, I. G. Production of cosmogenic isotopes $7 \mathrm{Be}, 10 \mathrm{Be}, 14 \mathrm{C}, 22 \mathrm{Na}$, and $36 \mathrm{Cl}$ in the atmosphere: altitudinal profiles of yield functions. J. Geophys. Res. Atmos. 121, 8125-8136 (2016).

37. Zängl, G., Hoinka, K. P., Zängl, G. \& Hoinka, K. P. The tropopause in the polar regions. J. Clim. 14, 3117-3139 (2001).

38. Wilcox, L. J., Hoskins, B. J. \& Shine, K. P. A global blended tropopause based on ERA data. Part I: climatology. Q. J. R. Meteorol. Soc. 138, 561-575 (2012).

39. Usoskin, I. G., Mironova, I. A., Korte, M. \& Kovaltsov, G. A. Regional millennial trend in the cosmic ray induced ionization of the troposphere. J. Atmos. Sol.-Terr. Phys. 72, 19-25 (2010).

40. Genevey, A., Gallet, Y., Constable, C. G., Korte, M. \& Hulot, G. ArcheoInt: an upgraded compilation of geomagnetic field intensity data for the past ten millennia and its application to the recovery of the past dipole moment. 
Geochem. Geophys. Geosyst. 9, https://agupubs.onlinelibrary.wiley.com/doi/ epdf/10.1029/2007GC001881 (2008).

41. Knudsen, M. F., Henderson, G. M., Frank, M., Mac Niocaill, C. \& Kubik, P. W. In-phase anomalies in Beryllium-10 production and palaeomagnetic field behaviour during the Iceland Basin geomagnetic excursion. Earth Planet. Sci. Lett. 265, 588-599 (2008).

42. Nilsson, A., Holme, R., Korte, M., Suttie, N. \& Hill, M. Reconstructing Holocene geomagnetic field variation: new methods, models and implications. Geophys. J. Int. 198, 229-248 (2014).

43. Pavón-Carrasco, F. J., Osete, M. L., Torta, J. M. \& De Santis, A. A geomagnetic field model for the Holocene based on archaeomagnetic and lava flow data. Earth Planet. Sci. Lett. 388, 98-109 (2014).

44. Usoskin, I. G., Gallet, Y., Lopes, F., Kovaltsov, G. A. \& Hulot, G. Solar activity during the Holocene: the Hallstatt cycle and its consequence for grand minima and maxima. Astron. Astrophys. 587, A150 (2016).

45. Holmes, R. L. Computer-assisted quality control in treering dating and measurement. Tree-Ring Bull. 43, 69-75 (1983).

46. Denne, M. P. Definition of latewood according to Mork (1928). IAWA J. 10, 59-62 (1989).

47. Wieloch, T., Helle, G., Heinrich, I., Voigt, M. \& Schyma, P. A novel device for batch-wise isolation of $\alpha$-cellulose from small-amount wholewood samples. Dendrochronologia 29, 115-117 (2011).

48. Laumer, W. et al. A novel approach for the homogenization of cellulose to use micro-amounts for stable isotope analyses. Rapid Commun. Mass Spectrom. 23, 1934-1940 (2009).

49. Slota, P., Jull, A. J. T., Linick, T. W. \& Toolin, L. J. Preparation of small samples for $14 \mathrm{C}$ accelerator targets by catalytic reduction of CO. Radiocarbon 29, 303-306 (2006)

50. Tikkanen, P., Palonen, V., Jungner, H. \& Keinonen, J. AMS facility at the University of Helsinki. Nucl. Instrum. Methods Phys. Res. B 223, 35-39 (2004).

51. Stuiver, M. \& Polach, H. A. Radiocarbon. Radiocarbon 19, 355-363 (1977).

52. Helama, S., Arppe, L., Timonen, M., Mielikäinen, K. \& Oinonen, M. Agerelated trends in subfossil tree-ring $\delta 13 \mathrm{C}$ data. Chem. Geol. 416, 28-35 (2015).

53. Tocher, K. D. \& Gumbel, E. J. Statistical theory of extreme values and some practical applications. J. R. Stat. Soc. A. 118, 106 (1955).

54. Di Marco, V. B. \& Bombi, G. G. Mathematical functions for the representation of chromatographic peaks. J. Chromatogr. A 931, 1-30 (2001).

55. Tarandovskiy, I. D., Artemenko, E. O., Panteleev, M. A., Sinauridze, E. I. \& Ataullakhanov, F. I. Antiplatelet agents can promote two-peaked thrombin generation in platelet rich plasma: mechanism and possible applications. PLoS ONE 8, e55688 (2013).

56. Helama, S., Fauria, M. M., Mielikainen, K., Timonen, M. \& Eronen, M. SubMilankovitch solar forcing of past climates: mid and late Holocene perspectives. Geol. Soc. Am. Bull. 122, 1981-1988 (2010).

\section{Acknowledgements}

The authors thank Hanna Turunen and Anne-Maija Forss for sample preparations, Igor Shevchuk for IRMS measurements and Lukas Wacker for providing the GER data. The work has been supported by the Academy of Finland (grants 251287, 251441, 288083, 288267, 292788 and 272157/ReSoLVE Centre of Excellence).

\section{Author contributions}

M.O. and J.U. designed the study and performed the data analyses. M.O. and T.H. supervised the study. S.H., P.N. and H.M. performed the tree ring analyses. L.A. performed the stable isotope analyses. V.P. measured the ${ }^{14} \mathrm{C}$ intensities. I.U. and G.K. modelled the vertical cutoff rigidities and ${ }^{14} \mathrm{C}$ production rates. K.M. reviewed and commented on the manuscript. All the authors participated in discussions and in writing the manuscript.

\section{Additional information}

Supplementary Information accompanies this paper at https://doi.org/10.1038/s41467 018-05883-1.

Competing interests: The authors declare no competing interests.

Reprints and permission information is available online at http://npg.nature.com/ reprintsandpermissions/

Publisher's note: Springer Nature remains neutral with regard to jurisdictional claims in published maps and institutional affiliations.

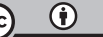

Open Access This article is licensed under a Creative Commons Attribution 4.0 International License, which permits use, sharing, adaptation, distribution and reproduction in any medium or format, as long as you give appropriate credit to the original author(s) and the source, provide a link to the Creative Commons license, and indicate if changes were made. The images or other third party material in this article are included in the article's Creative Commons license, unless indicated otherwise in a credit line to the material. If material is not included in the article's Creative Commons license and your intended use is not permitted by statutory regulation or exceeds the permitted use, you will need to obtain permission directly from the copyright holder. To view a copy of this license, visit http://creativecommons.org/ licenses/by/4.0/

(C) The Author(s) 2018 